\title{
DISCURSOS CRÍTICOS E POÉTICOS PARA UM NOVO SÉCULO
}

\author{
CRITICAL AND POETIC SPEECHES \\ FOR A NEW CENTURY
}

Nuno Júdice

\begin{abstract}
RESUMO
Um olhar sobre a poesia portuguesa do século XX na relação entre a teoria da criação poética e uma história dessa poesia no período que sucede ao Modernismo. Sem a preocupação de ser exaustivo, são propostas obras e autores que marcam a evolução desse pensamento apontando os mais significativos em cada geração.
\end{abstract}

PALAVRAS-CHAVE: Poesia contemporânea, Modernidade, Conceitos de poesia.

\section{ABSTRACT}

A survey on Portuguese poetry of the $20^{\text {th }}$ century in the relation between the theory of Poetic creation and a history of Poetry in the period after Portuguese Modernism. Without the finality of being exhaustive, significant works and authors are pointed to represent the evolution of each generation of that period.

KEYWORDS: Contemporary Poetry, Modernity, Concepts of poetry 
O pensamento poético português na primeira metade do século XX pode ser definido por duas concepções opostas daquilo que é a Poesia, e que são transmitidas por dois títulos de livros: «O mistério da poesia, Ensaios de interpretação da génese poética» de João Gaspar Simões (1931) e «O conhecimento da poesia» de Vitorino Nemésio (1958). Mistério e conhecimento são os dois pólos contrários dessa visão do que constitui a relação do crítico ou do teórico com o objecto de que estão a tratar. Se a palavra mistério remete para o espaço de sagrado alusivo à visão romântica e inspirada da poesia, conhecimento joga com o racionalismo e com o pensamento capaz de justificar ou explicar o efeito de «sublime» ou de belo que o poema é capaz de criar.

Nesta dicotomia vamos encontrar também uma oposição que irá perdurar ao longo do século XX, até aos anos 70, entre o espaço não universitário e o universitário. Gaspar Simões, o primeiro biógrafo de Pessoa vem de uma área não literária dado que a sua formação é Direito, mas rapidamente se converte num dos mais importantes críticos literários do seu tempo. A acusação de autodidacta que lhe foi feita várias vezes terá sido uma razão pela qual Simões, incansável nessa actividade que iria percorrer várias décadas do século até à sua morte, em 1987, manifestou grandes reservas em relação ao que ele designava por «poesia universitária», considerando que um poeta em que fosse visível uma presença da teoria literária seria prejudicado por um excesso de intelectualismo que contrariava o seu conceito de poeta inspirado. Pelo contrário, Vitorino Nemésio doutorou-se em Letras e foi professor ao longo da sua vida entre a Bélgica, a França, o Brasil e Portugal. Terá sido isso que prejudicou uma recepção ampla da sua poesia, facto de que também se queixou o outro poeta universitário e grande intelectual que foi Jorge de Sena que tinha como modelos Camões e Pessoa no plano de uma visão da poesia como construção racional e intelectual.

Uma excepção nessa conciliação do mistério com o pensamento terá sido David Mourão-Ferreira pela sensibilidade lírica que é marca distintiva da sua poesia. Num pequeno e fundamental capítulo de «Discurso directo» intitulado «O poeta e o mundo dos sentimentos», David escreve sobre a desconfiança dos modernos em relação ao sentimento:

«Por outro lado, essa dissociação das palavras e dos sentimentos conduz-nos directamente a conceber o poeta como alguém que está sempre a fingir os sentimentos que exprime.» (p. 196).

E é a partir da «Autopsicografia» de Pessoa e da sua afirmação de que «o poeta é um fingidor» que Mourão-Ferreira refere que se pode tirar daí, a exemplo do "paradoxo sobre o comediante» do Diderot, o «paradoxo sobre o poeta» que consiste na sua impossibilidade de rejeitar, em poesia, o sentimento, mas ao mesmo tempo de não poder ignorar a poética da palavra. 
De um modo dramático, esta oposição já fora radicalizada por José Régio nos primeiros números da revista «Presença» (1927) ao dissociar literatura viva e literatura livresca. Régio defendia o lado experimental do poema, colocando a sua génese na experiência e no sentimento «real» do poeta, e manifestava um distanciamento crítico à poesia racional, pensada, calculada, tal como Edgar Poe o propusera na sua «Filosofia da composição» (em que explica a génese do poema «O corvo»). Esta sua atitude que retomava a ideia romântica da sinceridade poética afastava-o daquilo que Fernando Pessoa fizera com a criação dos heterónimos que, para Régio, não passavam de máscaras que visavam esconder o Eu do poeta.

Régio privilegia assim os poetas que partem da experiência e projectam na obra a sua vida, de preferência dramática ou trágica, sendo Mário de Sá-Carneiro o arquétipo ideal por ter vivido o seu conflito vivencial tão intensamente que acabou por se suicidar muito jovem; no seu oposto estão os que ele designa como intelectuais, jogando apenas no plano do pensamento, de que Pessoa será um exemplo. Nesta oposição entre Sá-Carneiro e Fernando Pessoa, o primeiro reflectindo a agonia do seu ser que não se conseguiu adaptar ao seu corpo e ao mundo, o segundo construindo uma obra artificiosa e vazia de sentimento, Régio projecta uma visão que decorre da estética presencista de recurso à psicologia, o que, no entanto, não o impede de reconhecer em Pessoa um Mestre.

Esta dualidade da nossa poética manter-se-á ao longo de várias décadas do século, muitas vezes tornando incompreendidos ou rejeitados alguns poetas que saíam fora desse molde da «vida» como fonte do poema. É nos anos sessenta, com o aparecimento da «Poesia 61» cujas propostas inovadoras nascem de um novo conceito de palavra como «significante», que o divórcio com a crítica tradicional se acentua, não deixando de prosseguir já nos anos setenta em que esta tendência «intelectual» irá ser continuada e aprofundada no sentido de uma aplicação das propostas resultantes do desenvolvimento dos estudos de poética e de teoria da literatura.

Voltando a Gaspar Simões e a Vitorino Nemésio, a diferença entre a suas visões do poético consiste em que, enquanto para o primeiro «o mistério da poesia é o mistério da criação, o inacessível aos princípios racionais, à decomposição analítica», e «tentar o aprofundamento dum tal mistério é tentar um aprofundamento do próprio mistério da Vida» (Simões, 1931, p. 22), para o segundo «por conhecimento há-de entender-se o que uma receptividade pessoal comovida e afim possa revelar de aproximado à compreensão insuficiente da criação alheia.» (Nemésio, 1997, p. 21) Se, para Nemésio, a compreensão será sempre insuficiente, no entanto ela representa uma aproximação desse segredo que é a "criação alheia» e transporta um elemento de compreensão pessoal, por parte do leitor, do que para Simões é um «mistério». Assim, o objectivo da crítica, para Simões, não se esgota no plano da compreensão do texto porque este é apenas um decalque da Vida, e ao analisar um poema o que se está a fazer é um esclarecimento desse mistério da vida, ao contrário de Nemésio que não pretende ir tão longe. 
José Régio é um caso singular neste contexto. A sua poesia nasce do seu conhecimento e da sua compreensão da poesia anterior, desde o Romantismo até ao Modernismo: e continuam originais e pertinentes muitas das observações quase sempre sintéticas que, na sua tese de licenciatura em Letras, abrangem o período que vai de Garrett a Pessoa. Nunca abdica de uma explicação pessoal de cada autor: mas é na conclusão do seu estudo que se interroga: «Que profundas, obscuras, subterrâneas, a-racionais correntes logram tocar-nos, a despeito (e - o que é mais espantoso - através) desse uso e abuso do cálculo intelectual na expressão estética?» (Régio, 1994, p. 207) E, não se sabe se por cálculo ou acaso, refere logo a seguir o «admirável tradutor» que foi Pessoa, citando «O Corvo» de Poe, de que Pessoa fez uma esforçada e notável versão portuguesa que o poeta refere ter sido feita «ritmicamente conforme com o original», o que vem demonstrar o seu interesse por um poema que, de acordo com a «Filosofia da composição, tenta desmitificar através da racionalidade que subjaz a cada palavra e a cada imagem, qualquer suspeita de génio sagrado ou de inspiração na criação poética. Mas Régio também entra em diálogo com Simões quando, sem referir directamente o livro em que ele coloca o «mistério da poesia» numa zona inapreensível ao espírito crítico, diz acerca de Pessoa que «as mais profundas raízes da sua poesia mergulham numa apreensão do sentido oculto de tudo, do mistério que tudo prolonga; e talvez nasça aí aquela magia que não podemos deixar de reconhecer a uma poesia em que, por outro lado, sentimos vários limites e cadeias» (Régio, 1994, p. 207).

Ao colocar itálicos em «sentido oculto» e em «mistério», e ao dizer que o poeta os apreende e prolonga, Régio retira-lhes esse lado místico e sacral que Simões reconhece como fazendo parte da essência do poético (um pouco como Sartre, para quem a poesia é inacessível à compreensão lógica, racional, aproximando-se mais da pintura - pela omnipresença da imagem - do que da linguagem). Podemos por isso situar Régio num ponto intermédio entre Simões e Nemésio nesta muito genérica mas essencial concepção daquilo que a poesia representa num plano mais essencial do que literário.

De fora deste percurso fica a corrente neo-realista que, a partir dos poetas do «Novo cancioneiro» (Coimbra, 1941-1944), de que se destacam Fernando Namora, Joaquim Namorado, Manuel da Fonseca, Carlos de Oliveira. Esta corrente que já surge na última fase da revista «Presença» tem como base a ideologia marxista e visa denunciar as duras condições de vida sob a Ditadura salazarista numa linguagem metafórica que dá expressão ao sonho de uma revolução operária e camponesa. Dada a natureza conjuntural deste movimento, não subestimando a importância que teve nesse momento histórico da década de quarenta, não será pertinente tratá-la a não ser pelo facto de terem surgido desse grupo poetas que, sem abdicar do ponto de partida realista, introduzem tópicos inovadores na sua escrita, como foi o caso de Carlos de Oliveira. 
Essa relação com o real que a estética marxista transporta para a criação poética será, a partir da década de 50, parodiada ou subvertida pelo nosso tardio surrealismo nas versões respectivamente de Mário Cesariny de Vasconcelos e de Alexandre O’Neill. No entanto, as alternativas ao neo-realismo surgem através de poetas que, sem ignorarem a necessidade de se oporem ao regime, não vinculam a poesia às suas posições políticas. Grupos como os que se formam em torno de publicações como «Os cadernos de poesia», a revista "Árvore» ou a proposta de uma «Poesia experimental» que, muito influenciada pela poética dos jogos visuais e fonéticos, tem um consistente teórico em E. M. de Melo e Castro e verá surgir as interessantes experiências de Ana Hatherly cuja obra se inspira nas invenções do período barroco.

A questão do realismo é questionada em poetas como Ramos Rosa que, enquanto crítico, encara a poesia como «interrogação do real», o que deveria conduzir a uma resposta; e de facto essa resposta tem de ser procurada no próprio poema que é a única expressão possível do que ele designa como «liberdade livre». É este princípio que vai influir nos poetas de 60 que trazem uma outra perspectiva de escrita mais ligada ao trabalho sobre a língua e a forma. O seu ponto de partida é a elipse anti metafórica que corresponde ao momento histórico da Poesia 61. Gastão Cruz define o que se poderia descrever, nessa época, como um projecto estético coerente e inovador na busca de uma superação do que, em todo o período do neo-realismo, fora o corte artificial entre conteúdo e forma, pondo de lado toda a poesia que não transmitisse uma «mensagem» (de preferência revolucionária). Como escreve Gastão, o fenómeno ao qual se refere como «característico da década de 40, a reconquista da autonomia da linguagem poética, é explicitado, pelas imediações de 1960, nos próprios textos de poesia.» (Cruz, 1999, p. 17). É também neste período que o trabalho sobre o fundo inconsciente da imagem adquire um papel na experiência do poético como viagem para o mundo interior, em Herberto Helder, sem dúvida o que mais se aproxima do surrealismo naquilo que essa estética trouxe de revolucionário na linguagem poética. Noutro plano, encontramos uma actualização da perfeição clássica, em Sophia, mas também no lirismo construído como escultura das sensações em Eugénio de Andrade.

Ruy Belo indica uma outra linha que recupera a experiência intertextual de Jorge de Sena, tanto como o diálogo com poetas referenciais da nossa cultura, ao mesmo tempo que introduz no poema um retrato das experiências poéticas sempre transmutadas numa visão reflexiva do mundo e do homem que vai para além do puramente poético. E quando disse que Fernando Pessoa era o «poeta vivo» que lhe interessava mais, estamos sem dúvida perante um dado fundador do momento em que Pessoa sai das muitas sombras e equívocos que o envolviam, para se tornar uma referência obrigatória para quem escreve poesia.

Nos anos setenta esta tendência irá ser continuada e aprofundada no sentido de uma aplicação das propostas resultantes do desenvolvimento 
dos estudos de poética e de teoria da literatura. Continuamos na linha teórica, de raiz universitária, mas agora mais centrada num trabalho inspirado na teoria da literatura dos formalistas russos e seguidores, e na revelação dos escritos pessoanos sobre o que é o sujeito e o poético (o que irá produzir nos manuais recentes a figura do «sujeito poético» em substituição do Poeta, conceito demasiado impregnado de romantismo). Em todo o caso, o que ainda aqui se verifica é uma continuidade relativamente à tradição que se pode designar como moderna, partindo do Modernismo, assimilando as grandes questões colocadas pela doutrina pessoana sobre o sujeito e prosseguida ao longo do século, e finalmente tentando o que se pode chamar uma desconstrução desse mundo, como por exemplo num João Miguel Fernandes Jorge e na sua relação com a História que é actualizada e desmitificada, ou num Joaquim Manuel Magalhães que a cada instante questiona a afirmação, sentimento ou imagem anteriores, até ao momento final em que implode toda a sua poesia ao reduzi-la a poemas mínimos e muitas vezes sem uma significação perceptível; ou ainda num Vasco Graça Moura que elabora um complexo jogo de espelhos entre real, mito e sujeito, colocando a sua marca cultural e subjectiva no centro da imaginação poética.

Talvez se possa compreender essa atitude de Magalhães que resulta da rejeição de reencontrar um sistema inscrito no cânone e que retome uma tradição - que para João Miguel vem da História e de uma galeria mítica de figuras que iluminam comportamentos presentes, e para Vasco da própria literatura como constelação arquetípica que faz girar o mundo poético. São desfechos diferentes daquilo a que Pinto do Amaral deu o nome de pós-modernidade na poesia portuguesa. De facto, se entendermos que esta geração abriu caminho ao fim do Modernismo na medida em que este adquiriu o estatuto histórico de época literária, a designação está correcta. O que vem a seguir - fim da década de oitenta e década de noventa - é uma realidade que abre caminho ao século XXI em que se assiste ao desfazer de valores e de referentes que existiam para gerações anteriores; e foi também a questão do cânone, ainda que de modo indirecto, que trouxe essa ruptura devido ao peso que, para novas gerações, poderá ter trazido um século XX que, justamente, recebeu a designação de novo «século de ouro» da poesia portuguesa.

Olhando para o passado mais recente, poderíamos já apontar a última década do século passado como o culminar de uma evolução que teve início com a instauração do regime democrático, em 25 de abril de 1974, e a libertação plena das pressões que a Ditadura exerceu sobre a nossa literatura no aspecto censório e autocensório. Poderia indicar assim três nomes dessa última década e meia do século XX como decisivos, na abertura de linhas diversas para o século XXI. Refiro-me a Al Berto, Adília Lopes e Ana Luísa Amaral.

A poesia de Al Berto é um dos monumentos desse fim de século $\mathrm{XX}$ e retoma o impulso épico do poema e do verso longos. Será uma das suas fraquezas, por vezes, mas o facto é que, apesar de uma marginalidade vivida através de uma máscara que se poderia classificar como elegante ou 
snobe, todos os excessos são equilibrados por uma poética que não cede à facilidade e que vai buscar os seus modelos aos clássicos, antigos ou modernos, de Camões a Pessoa.

Adília coloca-se no espaço dessa ruptura que nasce de um jogo de paródia e subversão de todos os valores, quer literários ou estéticos quer morais. Talvez se possa dizer que ela escreve os seus poemas com a mesma ingenuidade infantil com que as crianças dizem palavrões, apenas para escandalizar os adultos; mas por trás dessa atitude há uma real provocação que é reforçada pelo vocabulário obsceno que, no entanto, tem sempre por trás um crucifixo ou um rosário a pedir absolvição.

Ana Luísa Amaral, por fim, inscreve neste espaço poético uma presença da dimensão feminina que não se deixa vencer por imposições ideológicas. Também nela não há qualquer facilidade ao militantismo que enfraquece, muitas vezes, a literatura «feminista», e esse ponto de vista (e de partida) desemboca numa poesia em que todos os grandes temas estão presentes, da solidão ao amor.

Se a estes poetas juntarmos o que se pode classificar como um regresso ao classicismo com a recuperação de formas tradicionais como o soneto ou a elegia, teremos em Luís Filipe de Castro Mendes, em João Luís Barreto Guimarães, em Jorge Reis-Sá, entre os que mais se destacam, uma outra via que nestes poetas abre caminho a uma revisitação dessas formas que constitui o ponto de partida para poéticas pessoais em que o referente cultural, em Castro Mendes, social em Barreto Guimarães e metafísico em Reis-Sá, constituem importantes linhas de um outro caminho estético que, noutro âmbito, também se manifesta em Luís Quintais. Jorge Reis-Sá, no prefácio à $3^{a}$ edição da antologia «Anos 90 e agora», em 2003, classifica a poesia deste período dizendo que «o lirismo vive em cada verso, é uma tradição longa e infindável. Não se tergiversará no propósito da beleza e do sublime. A melancolia é uma característica transversal a estas vozes, á qual se acrescenta a imagética, a metaforização, o próprio lirismo.» (Reis-Sá, 2003, p. 9).

Duas palavras são essenciais para marcar a poesia deste fim de século, no dizer de Reis-Sá: lirismo e melancolia. Já Fernando Pinto de Amaral, além de ter dado o nome clínico da melancolia a um dos seus livros, "Acédia», dedicou-se a um estudo sobre esse sentimento na poesia das últimas décadas do século. Mas se esta verificação do que se poderia designar como um neo-lirismo é interessante é porque revela, finalmente, uma diferença desta geração de 90 em relação ao que se diz ter caracterizado a poesia de setenta: a narratividade, o verso longo, a quase indistinção entre prosa e poesia. Também a sua observação de que, nesta poesia de 90, ao invés do que marca uma Adília Lopes ou até certo ponto um Al Berto, ressurge como questão o tema da beleza e do sublime como fontes da criação poética. Progressivamente, a partir desses anos setenta, foi Herberto Helder que se tornou o ícone de sucessivas gerações de poetas, por vezes 
erradamente devido a ser confundido com o arquétipo do poeta marginal, distante, maldito, devido ao seu recolhimento (aparente). O próprio Herberto, no fim da sua vida, quis romper com esse mito quando publica um livro sem a habitual limitação de tiragem que ele exigia para edições anteriores, o que é apontado como uma cedência ao «mercado». Esse livro, «Servidões» (2014), é alvo de críticas violentas devido ao jogo que o poeta faz com vários registos de língua, desde o mais elaborado, na linha da sua poesia inicial, ao discurso quotidiano e mesmo violentamente banal. $\mathrm{O}$ analfabetismo crítico, neste caso, foi incapaz de ver que esta é uma constante da sua poética, e se aqui se tornou mais visível foi porque Helder conseguiu atingir fundo os que, valorizando o chamado «quotidiano» e uma poesia nascida do imediato, os obrigou a ver a complexidade do trabalho poético helderiano e o fundo cultural (e social) que alimenta a sua poesia.

Perguntar-se-á qual a continuidade destas contradições, conflitos, visões opostas, estéticas diversas, que enriqueceram o século $\mathrm{XX}$, no século actual? A resposta não é fácil porque faltam visões de conjunto e que ponham em perspectiva o que se tem passado desde o início do século até hoje; e também é verdade que 15 anos são um tempo escasso para permitir olhar com um mínimo de distância e de rigor este período. Se temos, por um lado, poetas que vêm de gerações e períodos anteriores a prosseguirem o seu caminho próprio, o que hoje se verifica é uma dispersão de nomes e de propostas que muitas vezes se perdem quanto mais não seja pela falta de divulgação (resultante, nalguns casos, também de uma falta de vontade de divulgação). Esperemos que da espuma de tantas pequenas edições, colecções, editoras, que se vão sucedendo, algo emerja com a única autoridade possível num poema e num poeta: as suas qualidades de escrita e de invenção.

\section{REFERÊNCIAS BIBLIOGRÁFICAS}

SIMÕES, João Gaspar. O mistério da poesia. Coimbra: Imprensa da Universidade, 1931.

NEMÉSIO, Vitorino. "Conhecimento de Poesia», Obras Completas, Vol. XVII, Lisboa: Imprensa Nacional Casa da Moeda, $3^{\text {a }}$ ed., 1997 ( $1^{\text {a }}$ ed. Salvador da Bahia, 1958),

RÉGIO, Jose. «Pequena história da moderna poesia portuguesa», Crítica e Ensaios I, Obras escolhidas. Lisboa: Círculo de Leitores, Lisboa, 1994.

MOURÃO-FERREIRA, DAVID. Discurso directo, Guimarães editores, 1969.

CRUZ, Gastão. A poesia portuguesa hoje.Lisboa: Relógio d’Água, 1999. 
JORGE REIS-SÁ, seleccção e organização. Anos 90 e agora?. Famalicão: Edições Quasi, 2003.

Recebido para publicação em 02/04/2015

Aprovado em 22/08/2015

\section{NOTAS}

* Ensaísta, poeta, ficcionista e professor universitário no Departamento Línguas, Culturas e Literaturas Modernas da Universidade Nova de Lisboa. Licenciou-se em Filologia Românica pela Universidade de Lisboa e obteve o grau de Doutor pela Universidade Nova de Lisboa. 